Author manuscript

\title{
Background noise: a review of the effects of background infill on urban liveability in Perth
}

\author{
Julian Bolleter
}

To cite this article: Julian Bolleter (2016): Background noise: a review of the effects of background infill on urban liveability in Perth, Australian Planner, DOI: 10.1080/07293682.2016.1245201

To link to this article: http://dx.doi.org/10.1080/07293682.2016.1245201

Published online: 14 Nov 2016. 


\title{
Background noise: a review of the effects of background infill on urban liveability in Perth
}

\author{
Julian Bolleter \\ AUDRC, University of Western Australia, Perth, Australia
}

\begin{abstract}
While Activity Centres and Activity Corridors are the flagships of Western Australian State Government urban infill policy, much of infill development which is being delivered is 'background infill' - the subdivision of suburban lots to create two to five new dwellings. This paper assesses this background infill with reference to the State Government's goal of enhancing 'liveability' using criteria such as access to nature, cultural assets and public transport. The conclusion is that background infill is producing mixed results, in all of these areas, and that the policies producing such infill require attention.
\end{abstract}

\section{Introduction}

Perth's overarching planning document 'Directions $2031^{\prime 1}$ aims to achieve a city which is 'liveable, prosperous, accessible, sustainable and responsible' (Western Australian Department of Planning 2010, 43). Taking these aims at face value, this paper explores whether the predominate form of infill in Perth, 'background infill' (ad hoc infill development yielding fewer than five dwellings) is delivering the urban liveability that the State Government is aspiring to. The overarching research question structuring this evaluation is:

To what degree has background infill, in Perth to date, delivered the urban liveability that the Western Australian State Government is aspiring to through its planning for urban infill?

\section{Method}

The research methods employed to answer this question are twofold. Firstly, a geospatial driven modelling and correlational strategy (Swaffield and Deming 2011, 37 ) is used to find correlations, or otherwise, between sites of background infill and criteria which can be used to assess liveability - including access to nature, cultural assets and public transport. Secondly, an evaluative research strategy (Swaffield and Deming 2011, 39 ) is used to evaluate whether the mapped conditions indicate an increase or decrease in urban liveability. This written evaluation is carried out in relation to the geospatial mapping, in conjunction with surveys of community preferences, in particular the comparatively recent 'The Housing We'd Choose' housing preferences survey (Curtin University and Hames Sharley 2013), and Perth's overarching plan 'Directions
2031'(Western Australian Department of Planning 2010).

\section{Urban liveability}

Firstly, the definition of urban liveability that this paper will employ to assess background infill needs to be clarified. Indeed relationships between urban densification and urban liveability are very complicated. They involve many factors such as 'building height, design and aesthetics; building heritage; housing affordability; traffic congestion and parking space; open space and parkland; and additional infrastructure and services for incoming residents' (McCrea and Walters 2012, 193). Compounding this complexity is that urban liveability also depends on residents' perceptions, which inevitably vary between individuals and suburbs (McCrea and Walters 2012, 193).

The Economist Intelligence Unit (EIU), which is responsible for the calculation of the EIU's wellregarded liveability index, employs a number of criteria to determine urban liveability which are based on a city's spatial characteristics (The Economist Intelligence Unit Limited 2012, 7). These include access to nature, cultural assets, public transport, amongst others (The Economist Intelligence Unit Limited 2012, 8). These three basic criteria also resonate in the housing preferences expressed by Perth's residents in comparatively recent surveys. For example, $69 \%$ of respondents surveyed in the 'The Housing We'd Choose' study regarded a dwelling being near a park or reserve as being important, and $77 \%$ the presence of trees, $73 \%$ having easy access to shops and $71 \%$ being near public transport (Curtin University and Hames Sharley 2013, 19). Furthermore, these same criteria are also 
promoted for as being the basis for Perth's planning in the city's overarching planning document (Western Australian Department of Planning 2010, 45). While the EIU's criteria for liveability have been applied globally, it is apparent they resonate in Perth both for resident's and State Government planners.

As such this paper adopts the criteria of access to nature (both in the form of urban forests and open space), access to cultural assets, and access to public transport as the basis for the following discussion on liveability.

\section{Background infill}

Since Perth's 1990 'Metroplan' strategy, Perth has had metropolitan scale planning which aimed to consolidate development in relation to efficient public transport routes (Department of Planning and Western Australian Planning Commission 2015, 12). These principles were further extended in Perth's 2004 'Network City' plan. This plan comprised two main elements: Activity Corridors and Activity Centres and cast Perth as a 'connected city' with higher densities around transport nodes and areas of employment (Department of Planning and Western Australian Planning Commission 2015, 12). This TransportOrientated Development (TOD) philosophy was retained in 'Directions 2031' (Department of Planning and Western Australian Planning Commission 2015, 21). ${ }^{2}$

While Activity Centres and Activity Corridors are the flagship of the current Western Australian Government infill strategy, a large amount of infill development is occurring through the 'do it yourself subdivision of backyards. This form of infill development is referred to as ad hoc subdivision or 'background' infill - namely small projects yielding fewer than five group dwellings (Department of Planning and Western Australian Planning Commission 2014, 107) (Figure 1). This background infill is characterised by semidetached, survey strata, group dwellings (generally single storey) organised around a communal driveway space leading to private garages adjacent to the dwellings.

The prevalence of background infill development is confirmed by Perth's Urban Growth Monitor publication - indeed between 2011 and 2012, infill projects where development resulted in between one to five new dwellings per lot (i.e. background infill) accounted for $81 \%$ of all the infill dwellings constructed in that period (Department of Planning and Western Australian Planning Commission 2014, 113). The data for 20112012 are not an anomaly either - this breakdown of infill dwelling types being generally consistent with the historical average across the Perth metropolitan and Peel regions (Department of Planning and Western Australian Planning Commission 2014, 113). Put simply, despite 25 years of TOD planning in Perth, more infill is being delivered in an ad hoc, 'background' manner than is being delivered through Strategic Activity Centres or Activity Corridors.

This divergent situation is acknowledged by the Department of Planning which predict that 'as the density potentials (as defined by the residential design codes or R-Codes) are fully realised, larger scale infill projects will play a pivotal role in achieving the infill dwelling targets' (Department of Planning and Western Australian Planning Commission 2014, 113). As they explain, the shift to larger scale infill projects has

yet to occur as access to finance and market conditions has constrained the appetite for investment in these types of projects. Over time, as larger scale infill projects are introduced and structure planning progressed, it is anticipated that projects with higher dwelling yields per lot will make up an increasing proportion of all infill developments. (Department of Planning and Western Australian Planning Commission 2014, 113)

While this may turn out to be true, this paper proposes that there is value in directing attention to the type of infill development that is generally being delivered (i.e. background infill) rather than what is being aspired to but may not eventuate at the scale predicted.

\section{Why is background infill development dominant?}

First and foremost, the reason that a high percentage of infill development is happening in an ad hoc manner reflects the difficulties of achieving Activity Centres, and to a less degree Activity Corridors. When considered at the metropolitan scale, the correlation of residential density and public transport found in Perth's Activity Centres appears commonsense, but on the ground it is not without its issues. These train stations often have heritage building stock, have fragmented land ownership, and are typically complex 'knots' of intersecting road and rail infrastructure (particularly where rail lines run in the middle of the freeway such as on Perth's northern and southern rail lines), and have expansive carparks so people can 'park and ride', which conflicts with the attempt to create urban walkable town centres. Furthermore, there is generally not much community desire to reside in TOD Activity Centre settings, due to concerns about train noise, privacy and commuter car parking (Holling and Haslam McKenzie 2010, 284). A number of other Activity Centres are also proposed around big box shopping malls, which are, in many respects, the antithesis of the dense urban villages proposed in Activity Centre planning - the malls being car dominated, disconnected from the surrounding urban form and not attractive residential environments.

Secondly, the predominance of background infill development is a result of the political structure by 


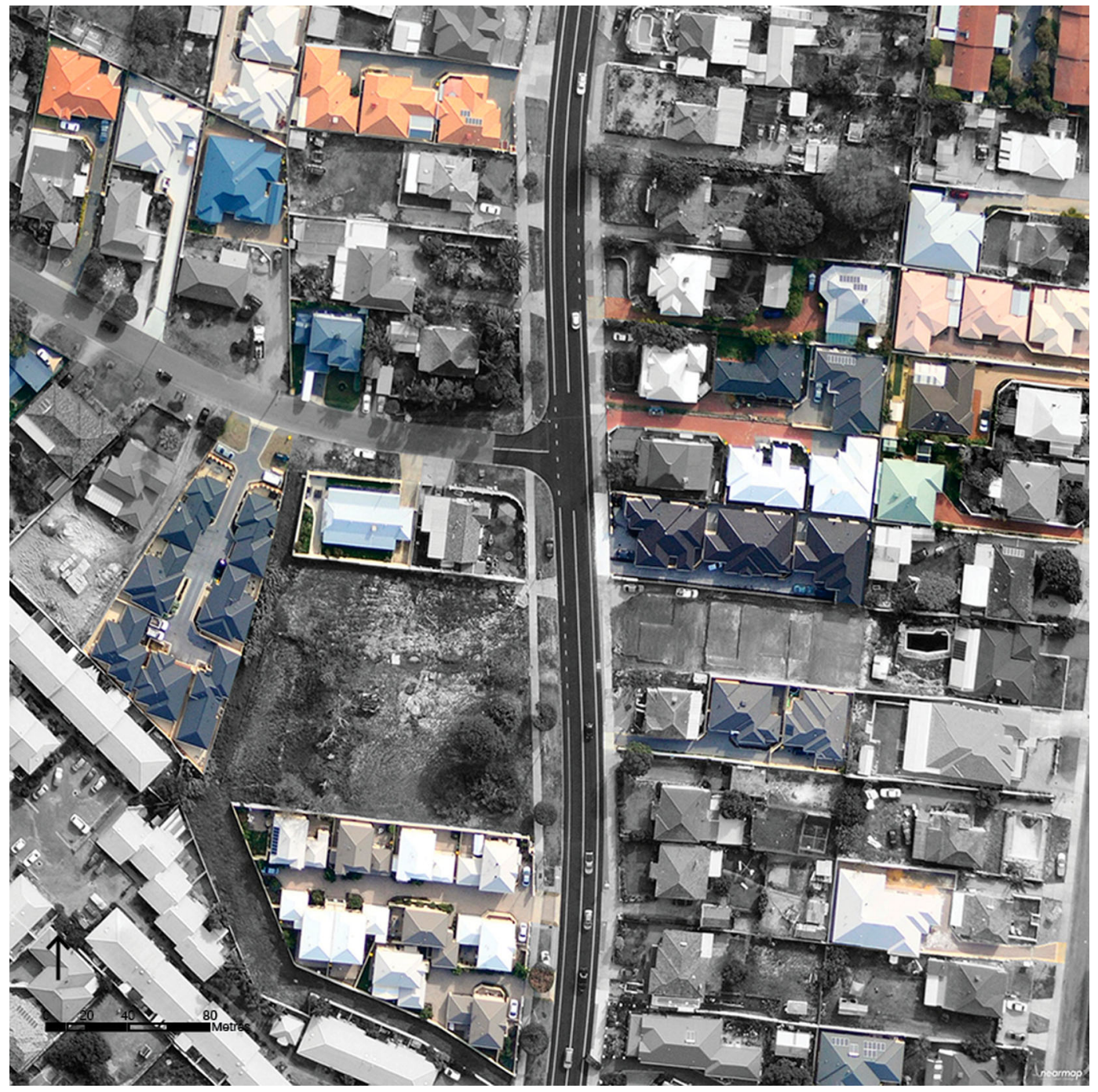

Figure 1. Background infill in a typical middle ring Perth suburb. Typical ad hoc subdivision or 'background' infill - namely small projects yielding fewer than five dwellings - in Perth's north eastern suburb of bayswater (Image courtesy of nearmap).

which infill development is realised. This structure is divided between local and state levels where the state sets infill targets for local government areas, yet local governments take much of the responsibility for infill development decisions (Dovey and Woodcock 2014, 68). Such local governments are frequently 'elected to enforce the anti-development views of their residents' and as such disperse as much infill development in a form which is as palatable to existing residents as possible (i.e. in a low to medium density and dispersed pattern) (Dovey and Woodcock 2014, 68). Furthermore, local councils are typically not funded or staffed to deal with the complications of transit-oriented development such as Activity Centres and Activity Corridors (Dovey and Woodcock 2014, 68) and as such defer to a reasonably easy to administer background infill model which can occur 'incrementally with unfolding market demand' (Gray, Gleeson, and Burke 2010, 336). In contrast, Activity Centres and Activity Corridors require determined government policy and investment (Gray, Gleeson, and Burke 2010, 336) and as such pose significant challenges for cash strapped local governments.
As a result of the situation described, there exists a 'divergence between the compact city imagined in metropolitan plans and what is occurring on the ground in Australian cities' (Gray, Gleeson, and Burke 2010, 336) and in Perth in particular. Put simply, entrenched TOD ideology has, for many, obscured the reality of what policies for infill development are actually achieving.

\section{Backgrounding liveability in Perth}

The following sections of this paper explore the nature of background infill development in Perth in relation to the Western Australian State Government's own goals to create a liveable city.

\section{Access to nature}

'Contact with nature' is regarded as a universal requirement of 'urban landscapes' (Arvola and Pennanen 2014, 8), a sentiment also strongly shared by Perth's residents (Curtin University and Hames Sharley $2013,68)$. Of course, 'nature' is a slippery term that 
needs further clarification. John dixon hunt has divided nature into three categories, respectively first nature, second nature and third nature. First nature is the pristine nature of wilderness, second nature refers to cultural landscapes which can be taken to include all the landscapes of our cities and 'third nature' a category which includes all parks and gardens (Hunt in Thompson 2011, 19). Given the lack of a pristine, untouched by man, nature within a sprawling city like Perth, this paper will refer to hunt's second and third categories as they express themselves in private and public open space and urban forests, respectively.

\section{Private open space amenity}

One criterion of liveability that features in the vast majority of urban liveability matrices is open space. Indeed, the Australian lifestyle is famed for the ability to 'live outdoors, in private' - a situation enabled by freestanding houses with front and back gardens, set out at a typically low density (Wheeler 2010, 47). Evidence of a predilection for private open space is that a separate house set within its own garden is the preferred dwelling type favoured by $78 \%$ of Perth's residents (Curtin University and Hames Sharley 2013, 4). This is for good reason, home gardens have been shown to be a major contributor to the quality of life (Syme, Fenton, and Coakes 2001, 161). Among other functions, the residential gardens provide for both active and passive recreation as well as the space to cultivate fruit and vegetables. Furthermore, it can provide an individually aesthetically pleasing environment and makes an important social statement' (Francis and Hester in Syme, Fenton, and Coakes 2001, 161). The ongoing psychological benefits of the home garden have also been well documented (Kaplan in Syme, Fenton, and Coakes 2001, 161).

Not surprisingly background infill development in Perth tends to provide much less garden area per person, than an un-subdivided 'classic' quarter acre block that provided approximately $1000 \mathrm{~m}^{2}$ per household (Seddon 1994, 27). Compounding this situation much of the open space that is provided in a background infill situation is residual space, generated by the State Government controlled Residential Design Codes (R-codes) which dictate a minimum $1.5 \mathrm{~m}$ setback between lot lines and building edges (State of Western Australia 2010) which when 'built out' tends to result in narrow corridors of private open space on a number of lot edges. A proclivity for private car parking adjoining private dwellings also means that, in

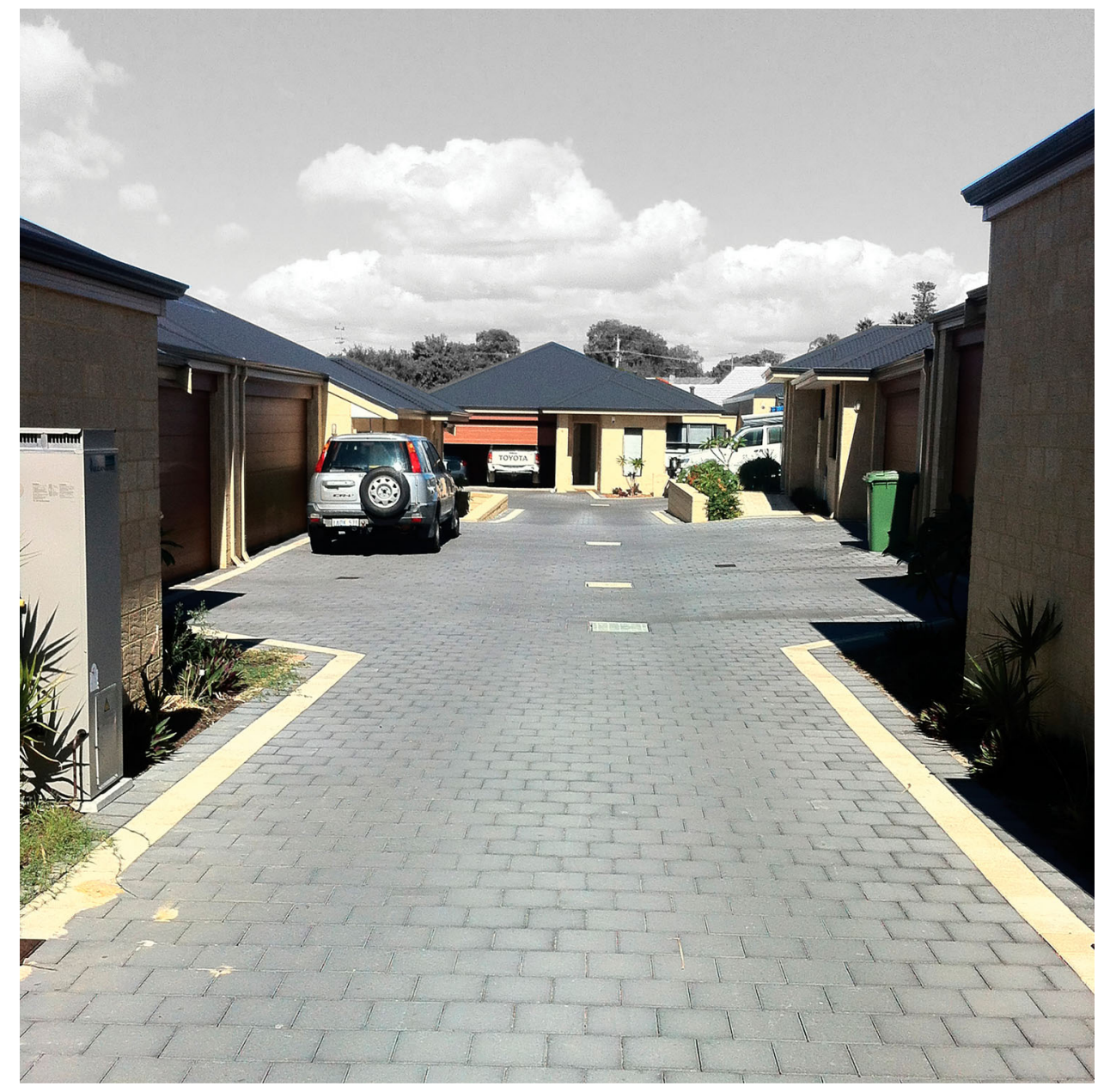

Figure 2. Typical background infill development. Background infill is characterised by semidetached, survey strata, group dwellings (generally single storey) organised around a communal driveway space leading to private garages adjacent to the dwellings. 
many cases, some $40 \%$ of the lot area is dedicated to car parking and movement (Figure 2).

\section{Public open space amenity}

The loss of private open space is only partly compensated for in the public realm, despite the fact that $69 \%$ of people in Perth think residing near a park is important (Curtin University and Hames Sharley $2013,68)$. While middle ring local government areas provide a substantial $40 \mathrm{~m}^{2}$ of public open space per person (Figure 3) - it tends to be of a poor quality and is sometimes not well utilised - evidence of which can be found in data concerning physical inactivity levels in residents (Figure 4). Perhaps this is because, across Perth's inner and middle ring suburbs where most background infill is occurring parks are poorly designed being typically turfed, sometimes having only scattered remnant trees. Reflecting this, among the parks in this area, $22 \%$ have no trees, only
$10 \%$ have significant wildlife function and only $1 \%$ have wetlands (despite the fact that Perth was historically a landscape of wetlands) (Centre for the Built Environment and Health 2013). Furthermore, 74\% of parks have a pervasive underlay of reticulated turf poorly suited to Perth's drying climate, $54 \%$ have no walking paths, $16 \%$ have picnic tables and only $9 \%$ of parks have barbecue facilities (Centre for the Built Environment and Health 2013).

Despite the significant amount of background infill development that has occurred to date, as the data above attests there has been no systematic upgrade of the public domain to service these higher density residents. This is in contrast with New South Wales where developers are required to make contributions to local councils for open space needs, resulting from new development under Section 94 of the EPA Act 1979 (Searle 2011, 202). The failure of Perth's open spaces to be upgraded to compensate for the loss of private

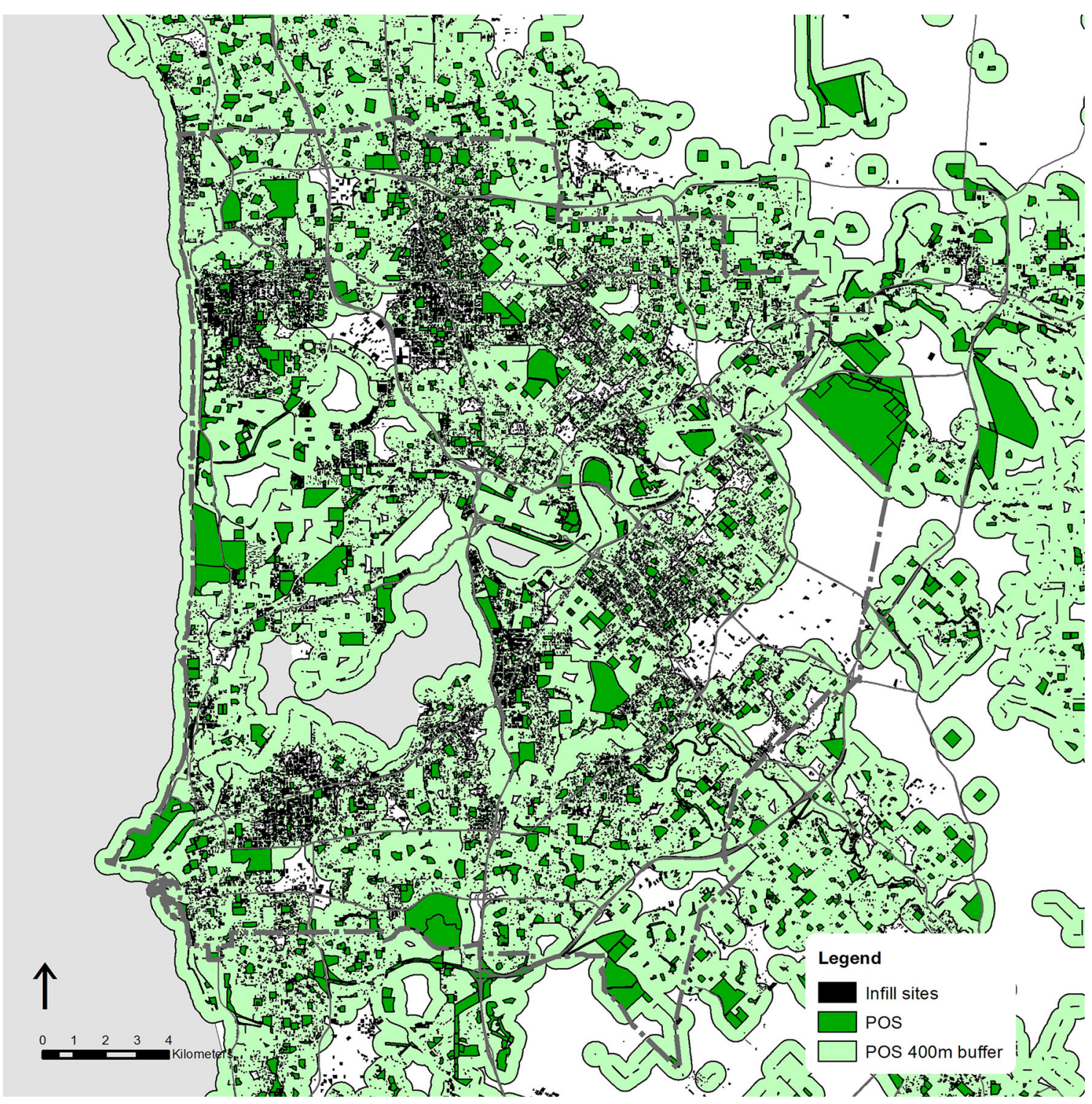

Figure 3. Public open space overlaid with background infill in the central subregion (CSR). Perth's CSR provides a high amount of public open space (POS), some $40 \mathrm{~m}^{2}$ per person. However, arguably the POSs in many of these urban areas are not well adapted to the needs of people residing in background infill (GIS data courtesy of Landgate and the Department of Planning). 


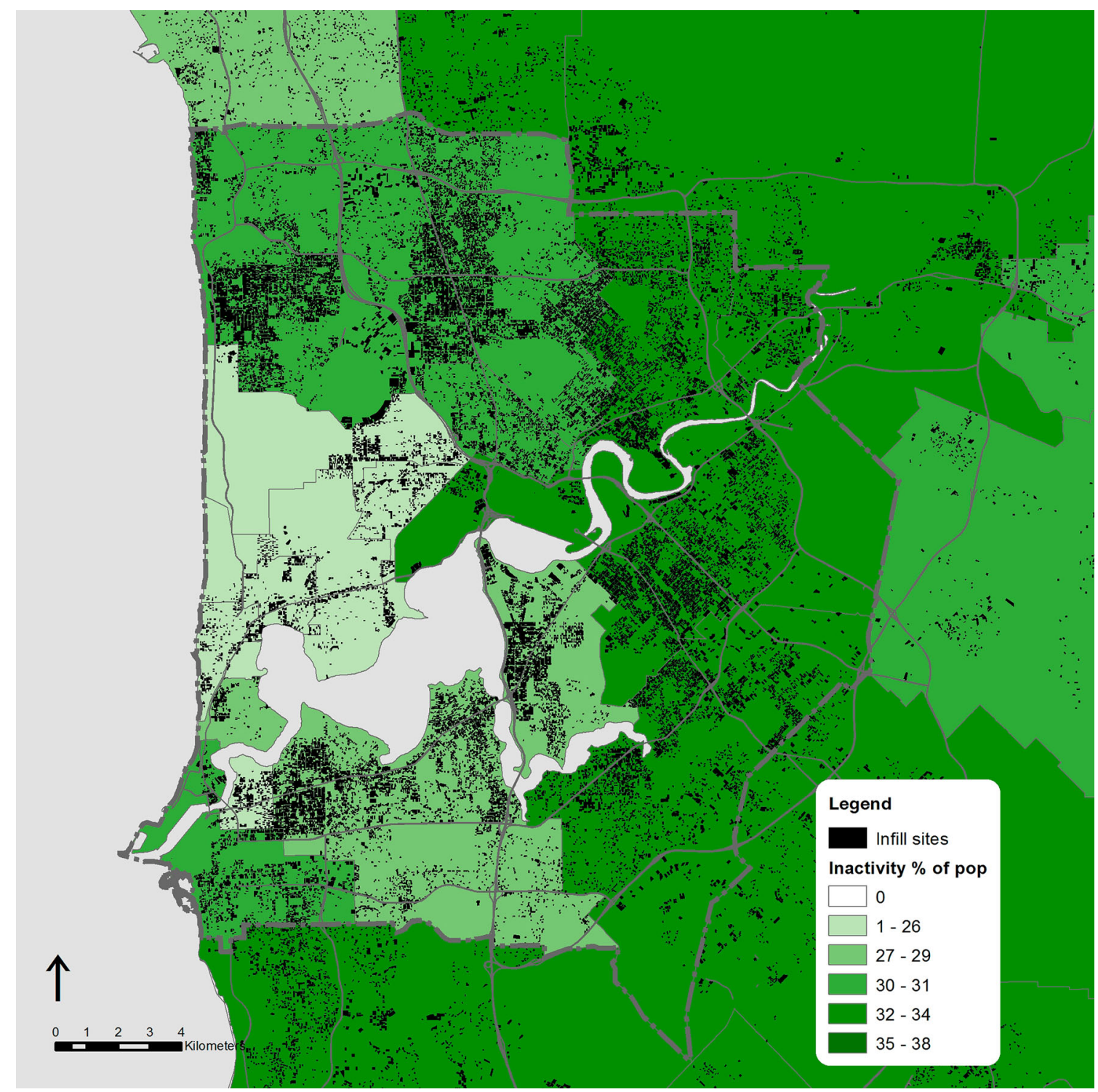

Figure 4. Inactivity levels (\%) overlaid with background infill. Local government areas with a significant amount of background infill development tend to be correlated with higher instances of physical inactivity; however, it is difficult to ascertain to what degree the reduction of private open space, and a generally poor quality public domain, is the cause of this (Data courtesy of The Australian social health Atlas and Landgate).

open space is important because research tells us that background infill residents require quite different things from the public space than their suburban counterparts.

For example, in a Perth study on the visitation of local parks and wetlands in smaller lot developments of $500 \mathrm{~m}^{2}$ or less (such as produced in background infill), it was found that there is increased visitation of wetlands but not parks (Syme, Fenton, and Coakes 2001, 168). These wetlands are characterised by 'natural vegetation at the lakeside through which visitors can walk, birdlife, remnants of native trees, playground equipment and some lawn for sports' (Syme, Fenton, and Coakes 2001, 163). Extrapolating from this finding, it would seem that residents in background infill are seeking a connection with 'nature' that may be missing in their much reduced and typically residual private open space domains, and in typically ecologically barren parkland (Centre for the Built Environment and Health 2013). Compounding this situation, access to major regional open spaces, which function as nature reserves in Perth (and existing somewhere between Hunt's first and second natures), are also limited in many of the rapidly densifying middle ring suburbs (Figure 5). Given the dearth of appropriately designed public open space, the relative inaccessibility of regional open space and a relative absence of private open space, background infill is arguably leading to a diminished quality of life for its residents, in this particular respect.

\section{The urban forest}

Evidence of the importance of the urban forest to urban liveability in Perth is that $77 \%$ of respondents to the 'The Housing We'd Choose' study considered that the 'presence of trees' is an important dwelling attribute (Curtin University and Hames Sharley 2013, 




Figure 5. Regional open space overlaid with background infill. A significant proportion of background infill development in Perth's northern CSR is not well served for regional open space (GIS data courtesy of the Western Australian Department of Planning (all not capitalised versions of DoP need to be updated) and Landgate).

19). Moreover analysis of house prices in Perth supports this. A comprehensive exercise to understand the value effects of tree cover found that the proportion of tree cover on neighbouring parks, reserves or street verges adjacent to the property, had a significant and positive impact on property prices (Pandit, Polyakov, and Sadler 2013, 16).

Despite the apparent importance of trees to supporting urban liveability in Perth, one effect of background infill has been a decline in urban forest cover in Perth's inner and middle ring suburbs. While there are some exceptions, the suburbs with the lowest percentage of urban forest cover tend to be those that have not resisted background infill (Figure 6). Examples of the effects of background infill development on urban forest cover can be found in the inner and middle ring suburbs of South Perth, Bayswater, Stirling and Canning (all which have high infill development targets) with the percentage of total vegetation cleared between 2001 and 2004 amounting to $13 \%, 12 \%, 11 \%$ and $11 \%$, respectively (McManus 2010, 350). One reason that background infill development has resulted in the removal of urban forest cover is a large proportion of urban trees are situated on private land - indeed this can be more than $60 \%$ (in Brunner and Cozens 2013, 234). Compounding this, trees and mature vegetation are often 'treated as trimmings to the designed urban environment and are afforded little or no protection against the exigency of meeting development aspirations' (Brunner and Cozens 2013, 232).

The clearing of this substantial urban forest has a number of potential ramifications for the provision of ecosystem services, and in turn urban liveability. In short, the urban forest provides environmental benefits, including reducing air pollution, sequestering greenhouse gasses (Brunner and Cozens 2013, 232), infiltrating and cleaning stormwater, minimising the impact of heat islands, ameliorating the local climate, and 


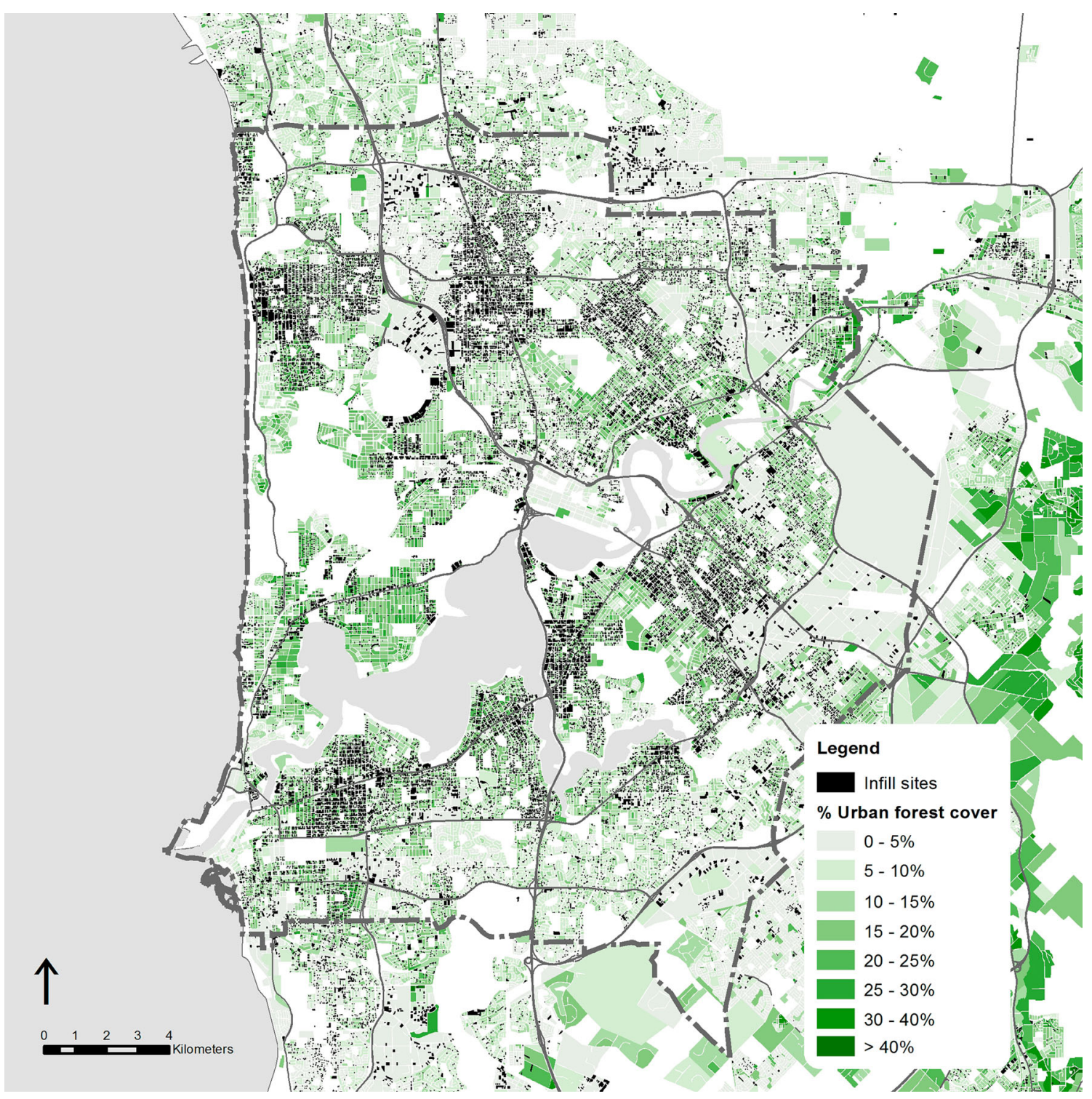

Figure 6. Percentage urban forest cover by suburb overlaid with background infill in the CSR. Wealthy suburbs which have tended to resist infill typically have a higher percentage of forest cover ( 20\%). In the north eastern suburbs of the CSR, background infill tends to be correlated with $\sim 10 \%$ forest cover (GIS data courtesy of the Western Australian department of planning and Landgate).

supporting biodiversity (Department of Planning and Western Australian Planning Commission 2015, 55). The partial clearing of an urban forest for background infill development threatens the provision of these ecosystem services - services which are often provided in traditional, un-subdivided, vegetated suburban form (Seddon 1994; Troy 2004; Hall 2010) - and arguably seriously diminishes the liveability of an urban area.

\section{Access to cultural assets}

An important facet of urban liveability is defined by the EIU as access to cultural assets $(2012,8)$. Cultural assets is a vague term and at one end of the scale can refer to world class cultural attractions such as an opera house and at the other end of the scale, a local community centre, café or shop. At the more modest end of this scale, 'easy access' to cultural assets such as local shops is regarded as a crucial dwelling attribute by Perth's residents - indeed $73 \%$ of respondents to 'The Housing We'd Choose' thought this was an important dwelling attribute (Curtin University and Hames Sharley 2013, 19).

So to what degree is background infill resulting in this latter form of cultural assets in Perth? Provision of cultural assets can be established in part through the mapping of Primary City Centres, Secondary Town Centres, and major and minor growth areas as defined in Perth's Activity Centre policy. The higher order centres in this network will include discount department stores, supermarkets, convenience goods, small-scale comparison shopping, personal services and some specialty shops (State of Western Australia 2005, 4146). The lower order centres tend to include a supermarket, personal services and convenience shops (State of Western Australia 2005, 4146).

When these general centre types are plotted against areas of background infill, there would appear to be a 
large proportion of residential areas which are largely devoid of such centres (Figure 7). This can be attributed to the dispersed nature of background infill which does not result in the densely populated urban precincts. As Debra Goostrey, Ex Chief Executive of the Western Australian Urban Development Industry Association explained:

When you get to (infill development) precincts, you can suddenly justify a small bar and a restaurant, you have to have enough people in and around that area ... density brings with it the coffee effect, that great vibrancy that comes through. [But] when you've got small little bits of density, you don't get the coffee shop effect ... (in Moodie and Trigger 2015)

In quantitative terms - while the Activity Centre policy defines 6250 residents per $\mathrm{km}^{2}$ as a desirable density to support Neighbourhood Centres (based on R25 gross density) even with background infill many Perth local government areas (such as the City of Stirling) only achieve a gross residential of 2100 people per $\mathrm{km}^{2}$ (Australian Bureau of Statistics 2013). Thus, while planning reports concerning compact cities are sometimes promoted with images of café culture and the convenience of local shops, it is not clear that the planning which perpetuates background infill is actually delivering this lifestyle. Beyond such population density stumbling blocks, the planning policies that produce background infill do not enforce developers to contribute to cultural amenities for local communities.

This is in contrast to cities such as Vancouver, which use an 'amenity bonus programme', in which developers provide public amenity contributions as

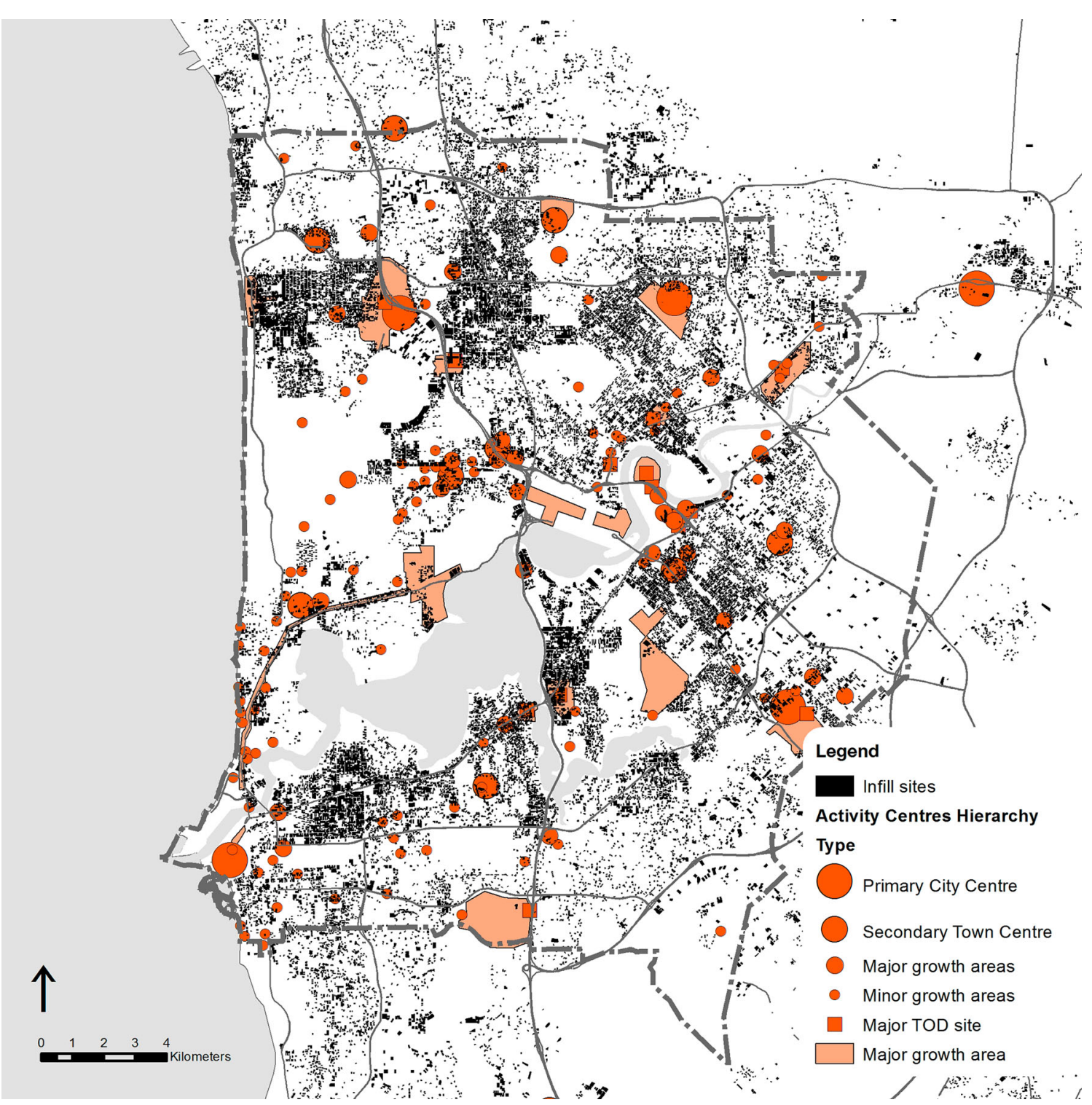

Figure 7. CSR Activity Centre and growth centre network overlaid with background infill. When the network is plotted against areas of background infill there would appear to be a significant proportion of densifying residential areas which are largely devoid of such centres. This can be attributed to the dispersed nature of background infill which does not tend to result in the densely populated urban precincts required to support significant cultural and commercial assets (GIS data courtesy of the Western Australian department of planning and Landgate). 
part of their urban development project (both in dollars and in the form of libraries, parks, childcare and community centres) partly to compensate for the impacts of higher density development on the existing community (OECD 2012, 120). Because of the small scale, dispersed and ad hoc nature of background infill in Perth such policies have not been pursued.

\section{Accessibility to public transport}

Both the EIU and the Western Australian State Government define a vital characteristic of urban liveability as being accessibility to public transport (Western Australian Department of Planning 2010, 45; The Economist Intelligence Unit Limited 2012). This sentiment would appear to be shared by Perth's residents, with $71 \%$ of respondents to the 'The Housing We'd Choose' survey indicating that a dwelling being near public transport was important (Curtin University and Hames Sharley 2013, 19).
Despite these preferences, Perth remains a car-centric city. Indeed 'over the past 40 years, the number of cars in Perth has grown faster than the population and it now has more cars per capita than any other Australian capital city with some 83 vehicles per 100 people' (Department of Planning and Western Australian Planning Commission 2015, 46). Reflecting this in 2011, 77\% of Perth residents drove to work. Of this group, $9 \%$ drove alone. Only a meagre $4 \%$ travelled to work either by cycling or walking (Department of Planning and Western Australian Planning Commission 2015, 47). In response to this situation, Directions 2031 emphasises the need to encourage alternatives to car travel, particularly by improving the relationship between land use and public transport ... and supporting the creation of neighbourhoods and Activity Centres that are based on walking, cycling and access to effective public transport services' (Western Australian Department of Planning 2010, 55). So to what degree is this accessibility to public transport provided

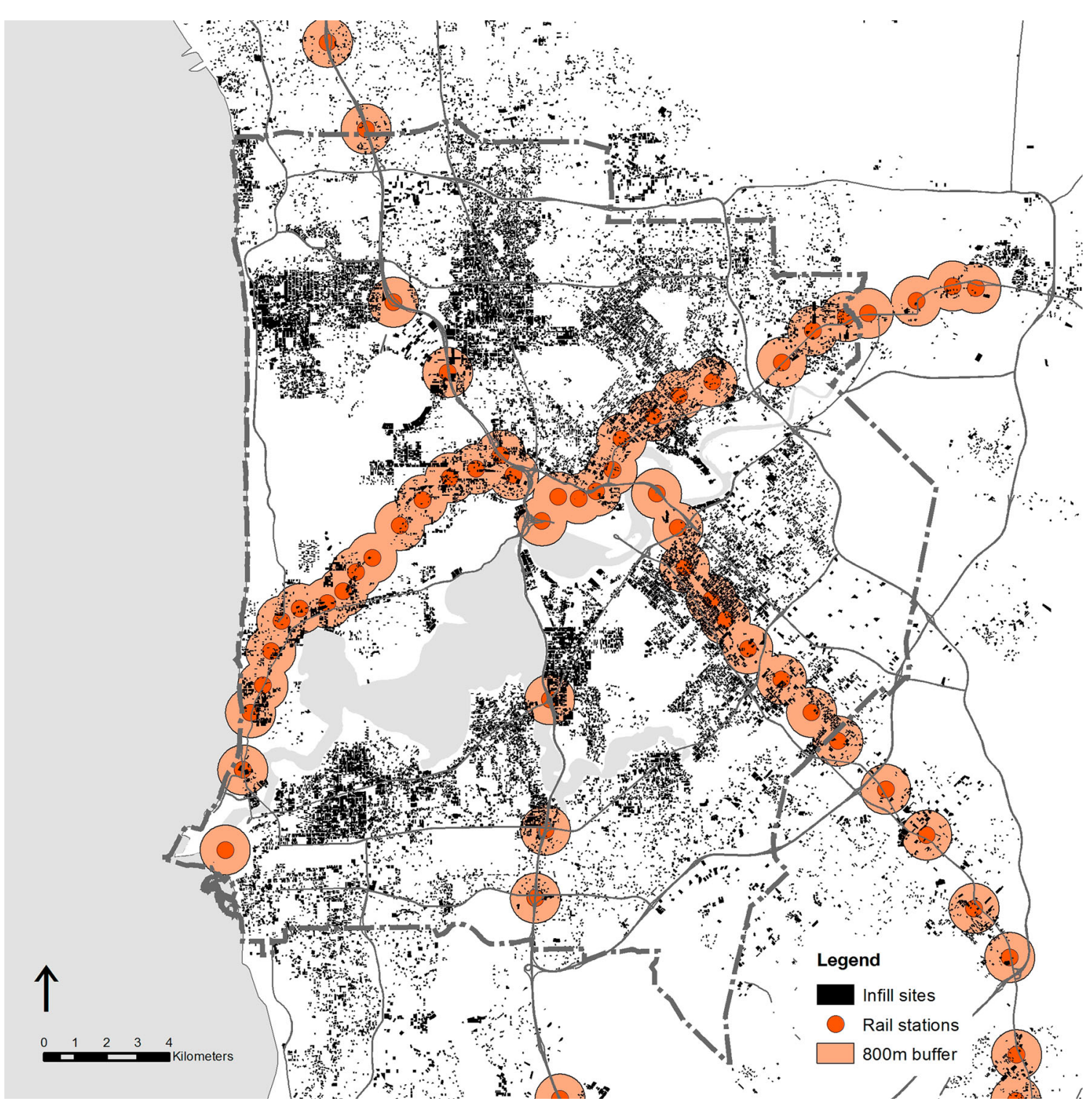

Figure 8. Train stations and their $800 \mathrm{~m}$ walkable catchments overlaid with background infill. Due to Perth's radial rail line pattern, large areas of background infill are not within walking distance of train stations (GIS data courtesy Landgate). 
in areas of background infill across Perth's inner and middle suburbs?

Perth's heavy rail system, the backbone of Perth's public transport system, consists of five major rail lines radiating from the city centre. Much of the background infill development that is occurring in middle ring suburbs is in the substantial areas between the radiating rail lines. Mapping of Perth's existing train stations in combination with background infill development which has occurred to date reveals that little of the background infill is within a short walk of train stations (Figure 8) - in this map shown as an $800 \mathrm{~m}$ or 10 minute walk. This situation is not unusual - in Sydney and Melbourne the highest concentration of medium - and even high-density housing is often in areas not served by rail services (Troy 2004, 122; Dodson 2010).
Due to this situation, public transport users in these background infill areas rely on Perth's bus system which either feeds into the rail system or accesses the city centre directly (Figure 9) shows bus stops with a greater frequency than 10 busses an hour during morning peak hour. While significantly more of the areas of background infill are serviced by bus routes than trains, the bus system tends to 'emphasise coverage' (i.e. short walking distances and the minimisation of bus transfers) at the cost of the 'frequency and legibility of the service' (Mees and Dodson 2011, 18). Perhaps due to such issues mapping of the proportion of people who drive, or are driven, to work reveals a high vehicular dependency in suburbs with a large amount of background infill, particularly in the northern most section of the middle ring suburbs (Figure 10).

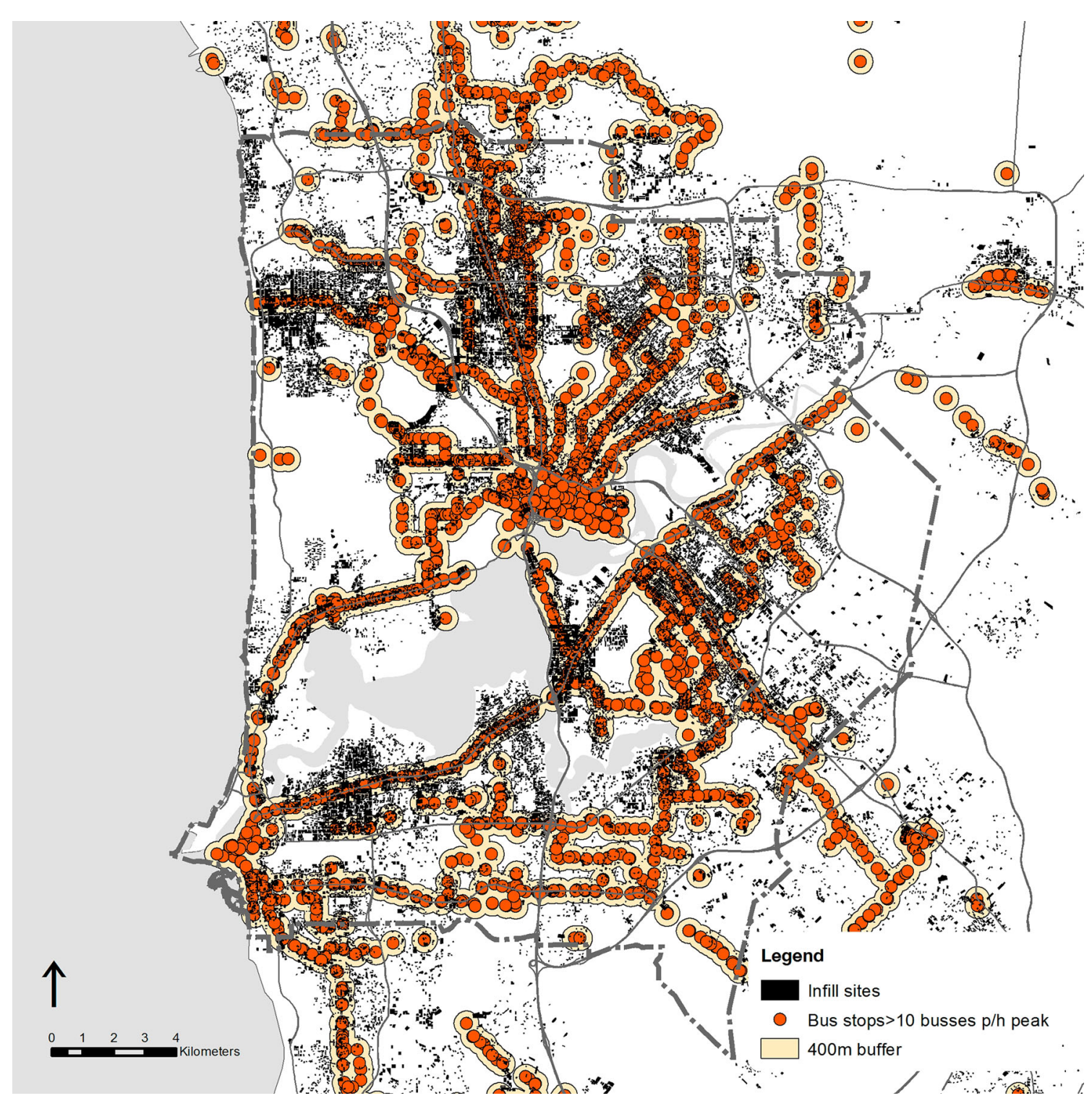

Figure 9. CSR bus stops with more than 10 services per hour (morning peak) and their $400 \mathrm{~m}$ walkable catchments overlaid with background infill. While significantly more of the areas of background infill are serviced by bus routes than trains, the bus system tends to prioritise coverage at the cost of the frequency and legibility of the service. Perhaps due to such issues mapping of the proportion of people who drive, or are driven, to work reveals a high vehicular dependency in suburbs with a large amount of background infill (GIS data courtesy Landgate and the Public Transport Authority). 


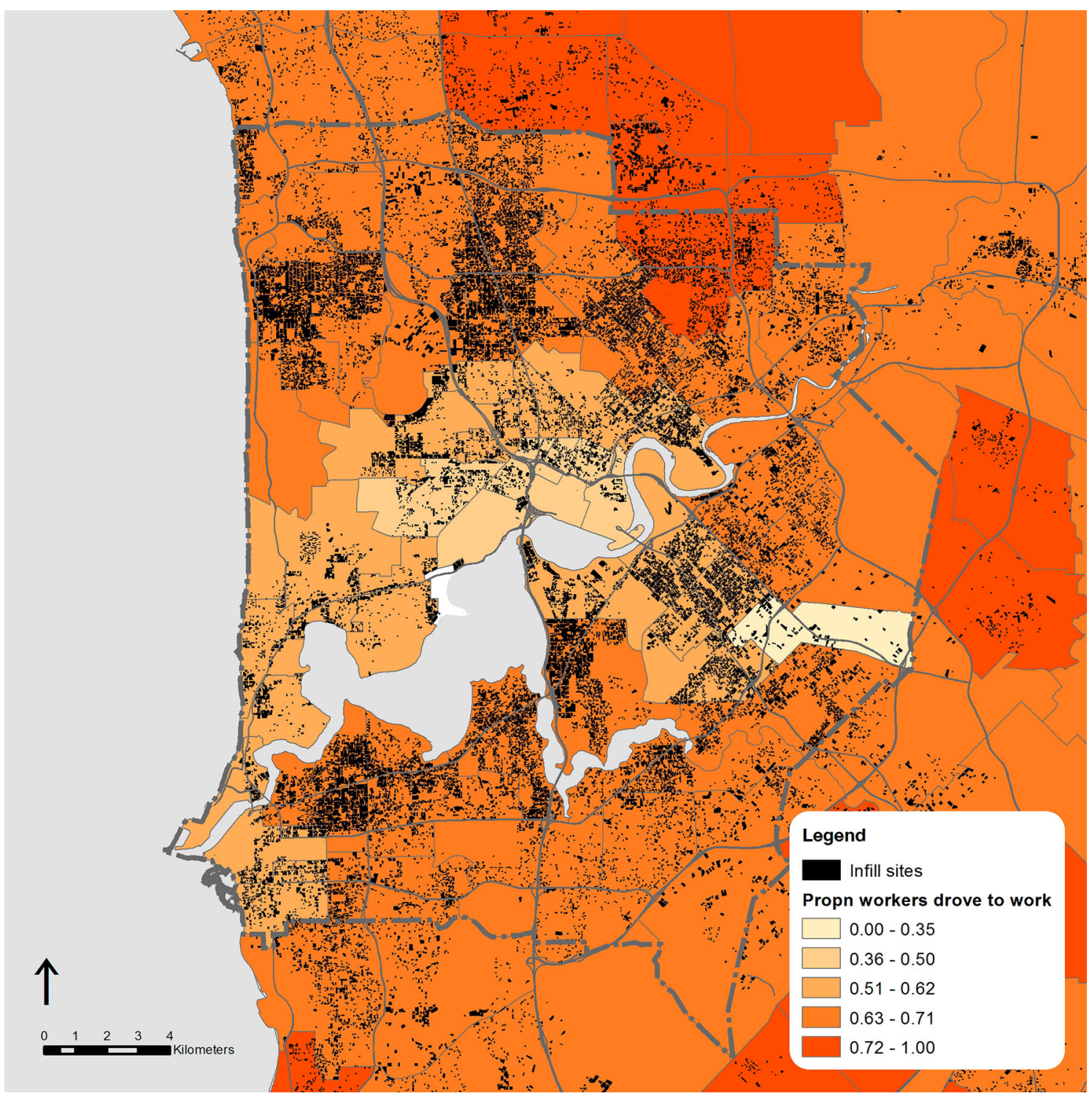

Figure 10. Proportion of workers commuting to work by car (alone) overlaid with background infill. Background infill development appears to have achieved a negligible decrease in car usage (GIS data courtesy of Australian Bureau of Statistics 2011 census and Landgate).

\section{Conclusion}

Arguably, an 'infill good, sprawl bad' polarity, has tended to pervade arguments about urban form in Australia (Gleeson 2006, 21), and the developed world more generally (Bruegmann 2005). In contradistinction we would argue, infill in the form of background infill is delivering mixed results in respect to urban liveability. Arguably the public open spaces in these densifying urban areas are not well adapted to the needs of people living in background infill - a situation that is compounded by diminished, residual outdoor space and a reduction urban forest cover associated with much of Perth's background infill development. Furthermore because of the incremental and ad hoc way, background infill is delivered, it is not producing the precincts of denser urban form that can support cultural and commercial assets to any large degree. Finally, much of the background infill is not well connected to public rail transport, a situation that is reflected in stubbornly high levels of car usage for commuting to work.

\section{Implications}

The implications of this situation are twofold. Firstly, one of the by-products of some of the negative liveability aspects of background infill has been an increasing resistance by local communities to infill development. Around Australia only 11\% of communities support infill development (Kelly, Breadon, and Reichl 2011) - a figure may be substantially lower in Perth given its lower average density than cities on the East Coast of Australia. One reason for this community sentiment is that the adverse effects of background infill (for example the clearing of the urban forest) have, to date, not being directly dealt with in planning. To 
deal with such potential adverse effects of infill development policies, some cities incorporate minimisation policies into their policies. High profile examples include Portland's green infrastructure initiatives for re-establishing the hydrologic cycle and combating urban heat islands (OECD 2012, 22). Ultimately if background infill cannot be delivered in a way that enhances the quality of life of urban residents - such as it reputedly is in Portland (OECD 2012, 22) - it is likely to work against future attempts to achieve infill development in Perth. As the OECD reminds us lively and liveable urban centres help to contain the 'centrifugal' power of a metropolitan area (OECD 2012, 23).

Secondly, if the State Government is resolute about increasing urban liveability in conjunction with urban densification then alternative strategies are required which lessen the emphasis on background infill. Where these strategies are already enshrined in policy (such as Activity Centres and Activity Corridors) then research is required to understand why, from a spatial, governance, and economic point of view, these policies are not delivering infill development dwellings at a higher rate. Concomitantly, as background infill is likely to continue, further research needs to be conducted which explores how dispersed ad hoc infill development, in Perth, can be coordinated to leverage greater liveability outcomes for its residents (Duckworth-Smith 2015).

With Perth's population predicted to increase dramatically over the next 50 years - from 1.9 to potentially 6.6 million (Australian Bureau of Statistics 2013) the need to deliver high performing infill development is unlikely to ease - while this population growth represents a creativity opportunity which is likely to be unrepeated, if it is handled poorly it could be calamitous. As Brendan Gleeson reminds us - our cities must become the urban 'lifeboats' which will enable us to sail through the coming storms of resource shortages and climate change (Gleeson 2010, 131). In short delivering infill development in a manner that improves urban liveability will be one of the challenges that defines Perth's viability in this century.

\section{Notes}

1. Since the time of writing this plan has been replaced by the draft Perth and Peel@3.5million document (Department of Planning and Western Australian Planning Commission 2015).

2. Despite their philosophical similarities, 'Network City' and 'Directions 2031' are differentiated by a drop in the infill development target from $60 \%$ to $47 \%$ (Holling and Haslam McKenzie 2010, 280).

\section{Funding}

The impetus for this paper originated from a Australian urban Design research Centre report funded by the Western Australian Planning Commission.

\section{References}

Arvola, Anne, and Kyosti Pennanen. 2014. "Understanding Residents' Attitudes Towards Infill Development at Finnish Urban Suburbs.” In World SB14 Barcelona, edited by Unknown editor, 1-10. Barcelona: World SB14 Barcelona.

Australian Bureau of Statistics. 2011. Population Projections, Australia, 2012 to 2101. Australian Bureau of Statistics 2013. Accessed January 14, 2011. http://www.abs.gov.au/ ausstats/abs@.nsf/Lookup/3222.0main + features52012\% 20(base)\%20to\%202101.

Australian Bureau of Statistics. 2013. 3218.0 - Regional Population Growth, Australia, 2011-12. Australian Bureau of Statistics 2012. Accessed June 26. http://www. abs.gov.au/ausstats/abs@.nsf/mf/3218.0/.

Bruegmann, Robert. 2005. Sprawl: A Compact History. Chicago, IL: The University of Chicago Press.

Brunner, Julie, and Paul Cozens. 2013. "Where Have All the Trees Gone?' Urban Consolidation and the Demise of Urban Vegetation: A Case Study from Western Australia." Planning Practice \& Research 28 (2): 231-255.

Centre for the Built Environment and Health. 2013. Public Open Space (POS) Geographic Information System (GIS) Layer. University of Western Australia 2013. Accessed November 6. http://researchdata.ands.org.au/publicopen-space-pos-geographic-information-system-gislayer.

Curtin University, and Hames Sharley. 2013. The Housing We'd Choose: A Study for Perth and Peel. Perth: Department of Housing.

Department of Planning, and Western Australian Planning Commission. 2014. Urban Growth Monitor: Perth Metropolitan, Peel and Greater Bunbury Regions. Perth: Western Australian Planning Commission.

Department of Planning, and Western Australian Planning Commission. 2015. Draft Perth and Peel @3.5 Million. Perth: Western Australian Planning Commission.

Dodson, Jago. 2010. "In the Wrong Place at the Wrong Time? Assessing Some Planning, Transport and Housing Market Limits to Urban Consolidation Policies." Urban Policy and Research 28 (4): 487-504.

Dovey, Kim, and Ian Woodcock. 2014. Intensifying Melbourne: Trasit-Orientated Urban Design for Resilient Urban Futures. Melbourne: Melbourne School of Design, The University of Melbourne.

Duckworth-Smith, Anthony. 2015. "Backyard Bonanza: Improving the Quality of 'Popular' Suburban Infill.” Australian Planner 52 (4): 297-313.

Gleeson, Brendan. 2006. "Waking from the Dream: Towards Urban Resilience in the Face of Sudden Threat." Griffith University Urban Research Program.

Gleeson, Brendan. 2010. Lifeboat Cities. Sydney: UNSW Press.

Gray, Rowan, Brendan Gleeson, and Matthew Burke. 2010. "Urban Consolidation, Household Greenhouse Emissions and the Role of Planning." Urban Policy and Research 28 (3): 335-346.

Hall, Tony. 2010. The Life and Death of the Australian Backyard. Collingwood Victoria: CSIRO Publishing. 
Holling, C., and F. Haslam McKenzie. 2010. "Integrated Transit Orientated Development: Is it Appropriate for Perth?" In Planning Perspectives from Western Australia: A Reader in Theory and Practice, edited by I. Alexander, S. Greive, and D. Hedgcock, 274-288. Perth: Fremantle Press.

Kelly, J.-F., P. Breadon, and J. Reichl. 2011. Getting the Housing We Want. Melbourne: Grattan Institute.

McCrea, Rod, and Peter Walters. 2012. "Impacts of Urban Consolidation on Urban Liveability: Comparing an Inner and Outer Suburb in Brisbane, Australia." Housing, Theory and Society 29 (2): 190-206.

McManus, Phil. 2010. "Planning With and For Trees in Perth: Yesterday, Today and Tomorrow." In Planning Perspectives from Western Australia: A Reader in Theory and Practice, edited by I. Alexander, S. Greive, and D. Hedgcock, 340-353. Perth: Fremantle Press.

Mees, Paul, and Jago Dodson. 2011. "Public Transport Network Planning in Australia: Assessing Current Practice in Australia's Five Largest Cities." Griffith University Urban Research Program 34: 1-28.

Moodie, Claire, and Rebecca Trigger. 2015. "Perth Infill Backlash: Suburbs Fighting High-Density Development." ABC News 2015. Accessed September 6. http://www.abc. net.au/news/2015-06-08/perth-infill-backlash-suburbsfighting-high-density-development/6521460?WT.ac = localnews_perth.

OECD. 2012. Compact City Policies: A Comparative Assessment. OECD Green Growth Studies.

Pandit, Ram, Maksym Polyakov, and Rohan Sadler. 2013. "Valuing Public and Private Urban Tree Canopy Cover." Not yet published.
Searle, Glen. 2011. "Urban Consolidation and the Inadequacy of Local Open Space Provision in Sydney." Urban Policy and Research 29 (2): 201-208.

Seddon, George. 1994. "The Australian Back Yard." In Australian Popular Culture, edited by Ian Craven, 2235. Cambridge: Cambridge University Press.

State of Western Australia. 2005. State Planning Policy 4.2: Activity Centres for Perth and Peel. Perth: State of Western Australia.

State of Western Australia. 2010. State Planning Policy 3.1: Residential Design Codes. Perth: State of Western Australia.

Swaffield, Simon, and Elen Deming. 2011. "Research Strategies in Landscape Architecture: Mapping the Terrain." Journal of Landscape Architecture (Spring) 6 (1): 34-45.

Syme, Geoffrey, Mark Fenton, and Sheridan Coakes. 2001. "Lot Size, Garden Satisfaction and Local Park and Wetland Visitation." Landscape and Urban Planning 56: 161-170.

The Economist Intelligence Unit Limited. 2012. Best Cities Ranking and Report: A Special Report from the Economist Intelligence Unit. London: The Economist.

Thompson, Ian 2011. "Ten Tenets and Six Questions for Landscape Urbanism.” Landscape Research 37 (1): 7-26.

Troy, Patrick. 2004. "Saving Our Cities with Suburbs." In Griffith Review: Dreams of Land, edited by Julianne Schultz, 115-127. Brisbane: Griffith University.

Western Australian Department of Planning. 2010. Directions 2031 and Beyond: Metropolitan Planning Beyond the Horizon. Perth: Department of Planning.

Wheeler, Tone. 2010. "Garden Cities of Tomorrow: Upside Down, Inside out and Back to Front." In Griffith Review 29: Prosper or Perish, edited by Julianne Schultz, 46-56. Brisbane: Griffith University. 